Patrie Fériana (Tunisie). - Découvert par mon ami le Capitaine Vauloger de Beaupré.

Cette espèce fait partie dı même groupe que le Carcinops minima Aubé, et en diffère par la taille, le système de coloration et les caractères précités.

\title{
Note sur des Arachnides capturés par M. Mazauric dans la grotte de Trabuc (Gard)
}

\author{
Par E. Simox.
}

II. Galien Mingaud m’a communiqué quelques Arachnides capturés par M. Ma zauric dans la grotte de Trabuc, près Miolet (Gard), déjà connue des entomologistes comme habitat du Bathyscia Mioletensis. - Ces Arachnides se rapportent à deux espèces, un Leptoneta que je ne puis déterminer avec certitude, M. Mazauric n'en ayant recueilli que de jeunes individus, et un Pedanostethus qui me paraît nouveau et dont je donne ci-après la description sous le nom de $P$. Vazaurici.

Cette espècequi a le faciès du P. lividus Blackw., s'en distingue surtout par ses yeux beaucoup plus petits et plus écartés les uns des autres et par ses chélicères pourvues a la marge inférieure de deux petites dents rapprochées entre elles, mais largement séparées de la base du crochet.

Pedanostethus Mazaurici sp. nov. \& long. 3-4 mill. Cephalothorax ovatus sat convexus, fronte lata et obtusa, pallide fulvo-rufescens, parte cephalica pilis paucis seriatis munita. Oculi antici in lineam rectam, medii fusci parvi a sese spatio oculo vix angustiore distantes, a lateralibus (albis et duplo majoribus) spatio saltem duplo majore distantes. Oculi postici in lineam leviter procurvam, inter se sat late et fere aeque distantes, medii lateralibus paulo minores (spatiis interocularibus oculis saltem duplo majoribus). Area oculorum mediorum latior quam longior et antice quam postice multo angustior. Clypeus verticalis planus area oculorum paulo latior. Chelae robustae et longae, fulvo-rufulae, nitidae, marginibus sulci longis, inferiore dentibus parvis binis remotis, superiore dente majore et acuto angulari instructis, ungue longo. Sternum fulvum. Partes oris infuscatae. Abdomen breviter ovatum, convexum, albidum, parce et tenuiter nigro-crinitum, macula genitali parva nigra notatum. Pedes robusti, sat longe nigro- 
criniti, obscure fulvo-rufuli vel castanei, femoribus coxisque dilutioribus. - o long. 3 mill. Pedes-maxillares fere ut in $P$. lividn, sed tarso angustiore.

\section{Note sur un Polydesmus monstrueux [Mrr.]}

\section{Par H. Brölemann.}

Au nombre des Myriapodes recueillis récemment pendant une excursion a Fontainebleau, s'est trouvé un échantillon monstrueux. Les cas de monstruosités des organes copulateurs signalés chez les Myriapodes sont rares, il peut donc ètre intéressant de mentionner celui qui vient de me passer sous les yeux.

Il s'agit d'un mâle de Polydesmus complanatus. L. L'écusson dorsal du $7^{\text {e }}$ somite ne présente rien de particulier; il en est autrement pour
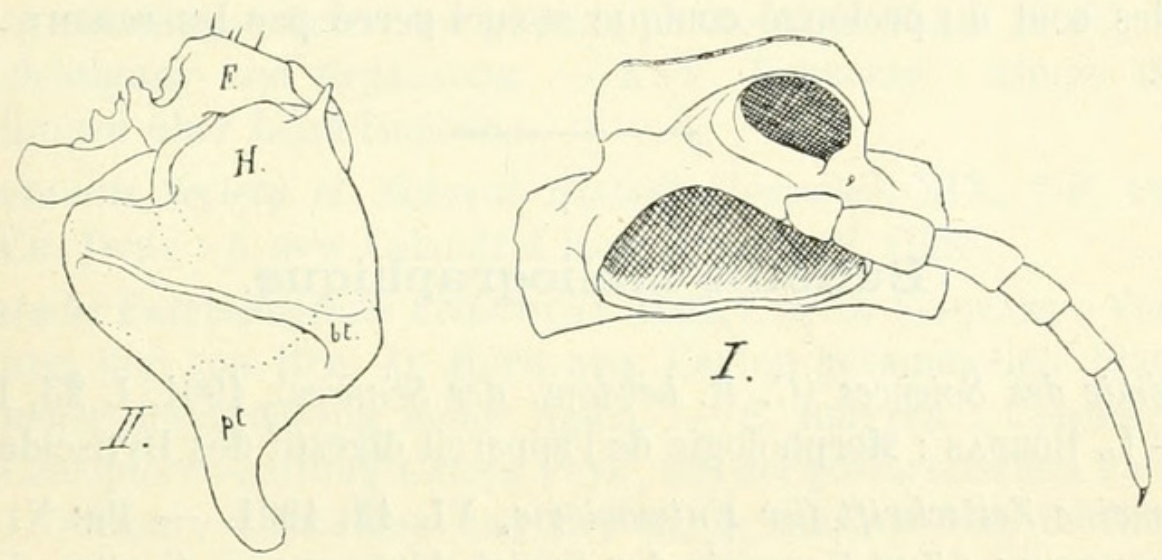

la face ventrale qui devrait porter quatre membres, une paire de pattes copulatrices et une paire de pattes ambulatoires. Chez notre sujet elle n'en porte que deux, la patte ambulatoire gauche, normale, la patte copulatrice gauche, comme le montre la figure I. Le còté droit est entièrement dépourvu de membres, on n'y voit pas davantage de traces de la trachée bien qu'il en existe une du còté gauche; la surface est normalement convexe et faiblement déprimée transversalement vers le milieu; par contre le bord postérieur du somite (face ventrale) est fortement échancré. L'échancrure ne se trouve pas sur la ligne médiane, mais précisément à droite de cette ligne. La crète du prozonite, qui fait suite à la suture, ou à l'étranglement transversal du dos, est un peu sinueuse à droite puis, arrivée à la hauteur de l'échancrure du bord postérieur, elle dévie fortement vers l'avant pour contourner l'ouverture coxale de la patte copulatrice gauche. 


\section{$2 \mathrm{BHL}$ Biodiversity Heritage Library}

Simon, Eugène. 1901. "Note sur les arachnides capturés par M. Mazauric dans la grotte de Trabuc (Garde)." Bulletin de la Société entomologique de France 1901, 238-239. https://doi.org/10.5962/bhl.part.17840.

View This Item Online: https://www.biodiversitylibrary.org/item/36400

DOI: https://doi.org/10.5962/bhl.part.17840

Permalink: https://www.biodiversitylibrary.org/partpdf/17840

\section{Holding Institution}

Smithsonian Libraries

\section{Sponsored by}

Smithsonian

\section{Copyright \& Reuse}

Copyright Status: NOT_IN_COPYRIGHT

This document was created from content at the Biodiversity Heritage Library, the world's largest open access digital library for biodiversity literature and archives. Visit BHL at https://www.biodiversitylibrary.org. 